\title{
Study on performance of old composite pavement reclaimed material in cement stabilized macadam base
}

\author{
Yuxuan Yang ${ }^{1}$, Peng Xiao ${ }^{1, \mathrm{a}}$, Shanshan $\mathrm{Xu}^{1}$, Tong Wang \\ ${ }^{1}$ College of Civil Science and Engineering, Yangzhou University, Yangzhou 225127, China
}

\begin{abstract}
For the old composite pavement, there are two regeneration methods: the overall recycling asphalt pavement and the cement concrete pavement and the Stratified recovery. C-B-3 gradation and cement content of $5 \%$ were used. The total content of recycled aggregate is $0,30 \%, 50 \%, 70 \%$ and $100 \%$ and the proportion of RA and RAP is about 1:2. Through compaction test, unconfined compressive strength test and dry shrinkage test, studying the feasibility of recycling composite pavement to cement stabilized macadam base. The results show that the strength of recycled cement stabilized macadam is generally higher than that of ordinary cement stabilized macadam. The strength of regenerated cement stabilized macadam can meet the strength requirements under most traffic volume of the highways in the standard. The gradation of the mixture by stratified recovery is more uniform and the quality of the mixture can be better controlled. The addition of NA has a negative effect on the dry shrinkage properties of recycled cement stabilized macadam. However, mixing RAP into recycled cement stabilized macadam can reduce the sensitivity of materials to water and enhance the dry shrinkage property of materials.
\end{abstract}

\section{Introduction}

The road base is the main bearing layer of the pavement. Its mechanical properties and durability have great influence on the service life of roads. Controlling the quality of the road base is the key to ensure the overall quality of the road surface ${ }^{[1]}$.Cement stabilized macadam is a mature technology widely used in road base ${ }^{[2]}$. Stone plays a supporting role in it, and strength is formed by the interlocking property between stones.With the rapid development of road construction in China, the demand for stone raw materials is increasing, but the stone materials can be mined is less and less. This partly curbed the sustainable development of road construction.

Construction waste can be processed into recycled aggregate after a series of treatments ${ }^{[3]}$. The use of recycled aggregate is very wide. In road engineering, it can be used to regenerate cement stabilized macadam base. The research ${ }^{[4][5][6]}$ shows that the development of mechanical performance index between recycled cement stabilized macadam and ordinary cement stabilized macadam is similar, such as unconfined compression strength, compressive resilience modulus, splitting strength etc.

The regenerated value of the old asphalt concrete pavement milling material is high. When it is used in the stable base of the inorganic binder, it can make the regenerated mixture get better dry shrinkage, anti temperature shrinkage, water stability and durability, and have good economic and social benefits ${ }^{[7][8][9]}$.

\section{Test materials and test methods}

\subsection{Test materials}

(1) Natural aggregate (NA): Use four sizes of natural aggregate, including NA $1 \#(26.5-31.5 \mathrm{~mm})$, NA 2\# $(13.2-26.5 \mathrm{~mm})$, NA $3 \#(4.75-13.2 \mathrm{~mm})$, NA $4 \#(0-$ $4.75 \mathrm{~mm})$.

(2) Recycled aggregate (RA): RA obtained by breaking the old cement concrete pavement plates, including RA 1\# (15-31.5mm), RA 2\# (5-15mm), RA 3\# (0-5mm).

(3) Reclaimed Asphalt Pavement (RAP): RAP obtained by milling the old asphalt pavement, testing the remaining aggregate after the extraction.

Performance index of NA, RA and the remaining aggregate of RAP after the extraction are shown in Table 1 and 2 .

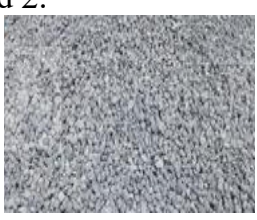

(a) NA

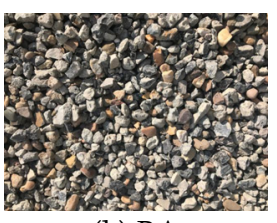

(b) RA

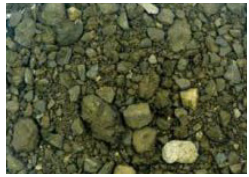

(c) RAP material

Figure 1. NA, RA and RAP material 
Table 1 Performance index of coarse aggregates

\begin{tabular}{cccc}
\hline $\begin{array}{c}\text { Material } \\
\text { specification } \\
(\mathrm{mm})\end{array}$ & $\begin{array}{c}\text { Needle like } \\
\text { content }(\%)\end{array}$ & $\begin{array}{c}\text { Crushing value } \\
(\%)\end{array}$ \\
\hline $\mathrm{N}$ & $26.5-31.5$ & 9.7 & $/$ \\
$\mathrm{A}$ & $13.2-26.5$ & 11.8 & $/$ \\
$\mathrm{R}$ & $4.75-13.2$ & 12.3 & 20.4 \\
$\mathrm{~A}$ & $15-31.5$ & 4.6 & $/$ \\
RAP material & $5-15$ & 7.3 & 22.5 \\
Required value & $\leq 18$ & 25.0 \\
\hline
\end{tabular}

Table 2 Performance index of fine aggregates

\begin{tabular}{cccc}
\hline $\begin{array}{c}\text { Material } \\
\text { specification } \\
(\mathrm{mm})\end{array}$ & $\begin{array}{c}\text { liquid } \\
\text { limit } \\
(\%)\end{array}$ & $\begin{array}{c}\text { Plasti } \\
\mathrm{c} \\
\text { index }\end{array}$ & $\begin{array}{c}<0.075 \mathrm{~mm} \\
\text { particle } \\
\text { content }(\%)\end{array}$ \\
\hline NA $(0-4.75)$ & 18.2 & 3.0 & 7.5 \\
RA $(0-5)$ & 23.9 & 6.1 & 2.8 \\
Required value & $<28$ & $<9$ & $\leq 15$ \\
\hline
\end{tabular}

(4)Cement: Using P.O.42.5 grade cement, the initial setting time and final setting time were 281 and $411 \mathrm{~min}$, the stability test result is $1.5 \mathrm{~mm}$, the compressive strength and flexural strength of 3D were 17.6 and 5.8MPa.

\subsection{Test methods}

In this paper, compaction test, unconfined compressive strength test and dry shrinkage test are carried out according to the standard test method in JTG E51-2009 $<$ Test Methods of Materials Stabilized with Inorganic Binders for Highway Engineering>. For the old composite pavement, there are two regeneration methods: the overall recycling asphalt pavement and the cement concrete pavement and the Stratified recovery. C-B-3 gradation and cement content of $5 \%$ were used. The total content of recycled aggregate is $0,30 \%, 50 \%, 70 \%$ and $100 \%$. Considering the thickness of the asphalt pavement of the original composite pavement is $10 \sim 12 \mathrm{~cm}$, the thickness of the cement concrete surface is about $24 \mathrm{~cm}$. The proportion of RA and RAP is about 1:2.

\section{Test results and analysis}

\subsection{Compaction test}

The best moisture content and maximum dry density are determined by heavy compaction method.The results are shown in Table 3.

Table 3 The best moisture content and maximum dry density

\begin{tabular}{ccc}
\hline Mixture type & $\begin{array}{c}\text { maximum dry } \\
\text { density }\left(\mathrm{g} / \mathrm{cm}^{3}\right)\end{array}$ & $\begin{array}{c}\text { best moisture } \\
\text { content }(\%)\end{array}$ \\
\hline 100\%NA & 2.412 & 5.8 \\
$70 \% \mathrm{NA}+30 \% \mathrm{RA}$ & 2.370 & 6.6 \\
$70 \% \mathrm{NA}+20 \% \mathrm{RA}+10 \% \mathrm{RAP}$ & 2.365 & 6.5 \\
$50 \% \mathrm{NA}+50 \% \mathrm{RA}$ & 2.304 & 7.3 \\
$50 \% \mathrm{NA}+33 \% \mathrm{RA}+17 \% \mathrm{RAP}$ & 2.993 & 7.1 \\
$30 \% \mathrm{NA}+70 \% \mathrm{RA}$ & 2.275 & 8.1 \\
$30 \% \mathrm{NA}+46 \% \mathrm{RA}+24 \% \mathrm{RAP}$ & 2.264 & 7.5 \\
$100 \% \mathrm{RA}$ & 2.257 & 8.9 \\
$66 \% \mathrm{RA}+34 \% \mathrm{RAP}$ & 2.245 & 8.1 \\
\hline
\end{tabular}

It can be seen from Table 3 that the best moisture content of cement stabilized macadam material is increased by replacing part of NA with RA. After adding PAP, the best moisture content can be reduced to a certain extent, but the decrease of the amount is not obvious. After adding RA and RAP into the cement stabilized macadam, the maximum dry density of the material will decrease, and the reduction is related to the total dosage of RA and RAP.

\subsection{Unconfined compression strength test}

The unconfined compressive strength of 7D is tested by two regeneration methods: the overall recovery and the Stratified recovery. Recording the intensity representative value of $95 \%$ guarantee rate $(\mathrm{Rc} 0.95)$ and the coefficient of variation $\left(\mathrm{C}_{\mathrm{V}}\right)$. The results are shown in Table 4 and 5 .

Table 4 Unconfined compression strength of 7D (Stratified recovery)

\begin{tabular}{ccc}
\hline Mixture type & $\mathrm{CV}_{\mathrm{V}}(\%)$ & $\mathrm{Rc} 0.95(\mathrm{MPa})$ \\
\hline 100\%NA & 8.76 & 4.08 \\
70\%NA+30\%RA & 7.66 & 4.28 \\
70\%NA+20\%RA+10\%R & 7.26 & 4.23 \\
AP & 8.31 & 4.43 \\
50\%NA+50\%RA & 8.79 & 4.49 \\
50\%NA+33\%RA+17\%R & 4.64 \\
AP & 6.95 & 4.53 \\
30\%NA+70\%RA & 6.63 & 4.87 \\
30\%NA+46\%RA+24\%R & 7.34 & 4.76 \\
AP & 7.11 & \\
100\%RA & &
\end{tabular}

Table 5 Unconfined compression strength of 7D (Overall recovery)

\begin{tabular}{ccc}
\hline Mixture type & $\mathrm{C}_{\mathrm{V}}(\%)$ & $\mathrm{Rc} 0.95(\mathrm{MPa})$ \\
\hline 70\%NA+30\%RA-RAP & 10.68 & 4.10 \\
50\%NA+50\%RA-RAP & 11.34 & 4.32 \\
30\%NA+70\%RA-RAP & 9.61 & 4.55 \\
100\%RA-RAP & 10.22 & 4.65 \\
\hline
\end{tabular}

It can be seen from Table 4 and 5 that the strength of recycled cement stabilized macadam is generally higher than that of ordinary cement stabilized macadam. The addition of RA in cement stabilized macadam can effectively improve its strength, which is due to the rough surface, sharp edges, and strong extrusion effect of RA. In addition, RA has low Needle like content and the old raw cement surface is coated with old cement mortar, which which releases heat second times during production. When both RAP and RA are used as recycled materials, the strength of cement stabilized macadam has little change. Although RAP does not possess several advantages of the above RA material, the old asphalt with RAP material itself can promote the adhesion of aggregate and enhance the performance of the mixture.

The coefficient of variation of mixture under stratified recovery is between $6.63 \sim 8.79$, which is smaller than that of 9.61 11.34 under overall recovery. 
In addition, the representative value of mixture strength is slightly larger, which indicates that the gradation of the mixture by stratified recovery is more uniform and the quality of the mixture can be better controlled. Because the amount of materials used in the laboratory is less, if the recovery process is strictly controlled and the uniformity of mixing is enhanced, the quality of the recycled mixture by overall recovery can be improved to a certain extent.

The strength of regenerated cement stabilized macadam is concentrated between 4.2 4.9MPa, which can meet the strength requirements under most traffic volume of the highways in the standard. In engineering application, the compressive strength can be adjusted by adjusting the amount of cement. Generally speaking, recycled cement stabilized macadam has wide application scope.

\subsection{Dry shrinkage test}

Selecting $0 \%, 50 \%$ and $100 \%$ three total content of recycled aggregate as representative for dry shrinkage test. The variation curves of total dry shrinkage strain and total water loss rate with time are shown in figures 2 and 3 .

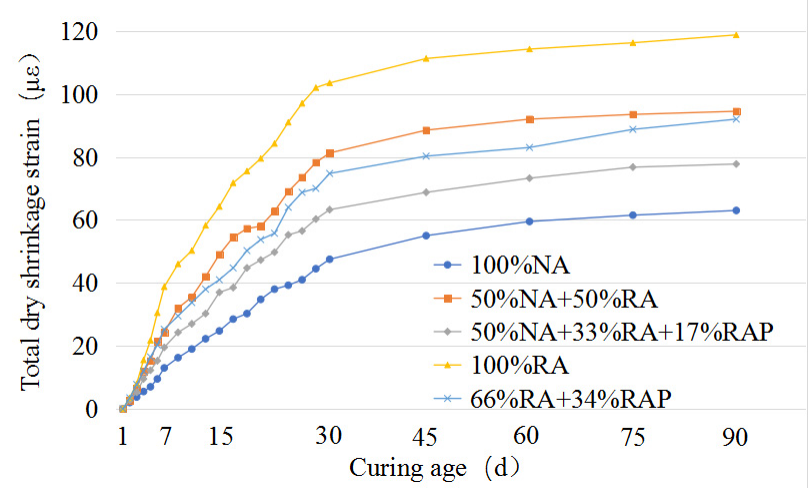

Figure 2. Variation curve of total dry shrinkage strain with time

From Figure 2, it can be seen that the total dry shrinkage strain of recycled cement stabilized macadam increases with time. In the early stage, their growth speed is fast, and as time goes on, the growth rate gradually slows down. When RA is added to the recycled cement stabilized macadam, the dry shrinkage strain of the material increases obviously. When the substitution rate of RA is $50 \%$ and $100 \%$, the total dry shrinkage strain of the material increase by $49.8 \%$ and $88.5 \%$. This indicates that the amount of RA is linearly related to the dry shrinkage strain of the material. This indicates that the amount of RA is linearly related to the dry shrinkage strain of the material. After mixing RAP into recycled materials, the dry shrinkage strain of recycled cement stabilized macadam is obviously reduced. It is indicated that RAP can significantly improve dry shrinkage properties of recycled cement stabilized macadam.

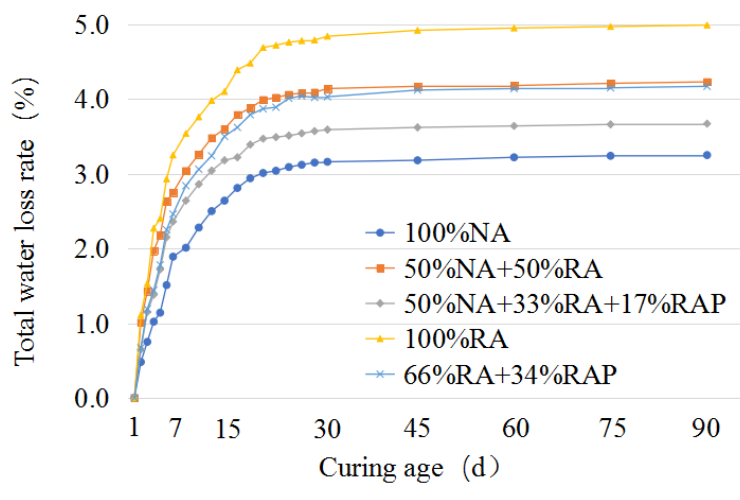

Figure 3. Variation curve of total water loss with time

It can be seen from Figure 3 that the total water loss rate of recycled cement stabilized macadam increases with time. In $0 \sim 20 \mathrm{~d}$, the rising trend of curve is obvious, then, the curve tends to be stable. When RA is added to the cement stabilized macadam, the water loss rate of the material increases obviously. When the substitution rate of RA is $50 \%$ and $100 \%$, the total water loss rate of the material increases by $30.2 \%$ and $53.5 \%$. This is because the water absorption of RA is larger than that of the RAP, and the surface of the RA is rough. In the process of infiltration, the water enters the pore of the aggregate, and the loss of water is larger in the measurement.

Table 6 Total dry shrinkage coefficient

\begin{tabular}{cc}
\hline Mixture type & $\begin{array}{c}\text { Total dry shrinkage } \\
\text { coefficient }\end{array}$ \\
\hline $100 \% \mathrm{NA}$ & 20.15 \\
$50 \% \mathrm{NA}+50 \% \mathrm{RA}$ & 25.30 \\
$50 \% \mathrm{NA}+33 \% \mathrm{RA}+17 \% \mathrm{RAP}$ & 23.91 \\
100\%RA & 29.83 \\
$66 \% \mathrm{RA}+34 \% \mathrm{RAP}$ & 25.12 \\
\hline
\end{tabular}

The calculated total dry shrinkage coefficient is shown in Table 6. It can be found that the dry shrinkage coefficient of the cement stabilized macadam increases with the addition of RA.

The material is more sensitive to the change of water loss rate. With the RA content increased, the dry shrinkage coefficient of cement stabilized macadam is greater. After mixing RAP into recycled materials, the dry shrinkage coefficient of recycled cement stabilized macadam is reduced. It is shown that mixing RAP into recycled cement stabilized macadam can reduce the sensitivity of materials to water and enhance the dry shrinkage property of materials.

\section{Conclusions}

(1) The strength of recycled cement stabilized macadam is generally higher than that of ordinary cement stabilized macadam. The strength of regenerated cement stabilized macadam can meet the strength requirements under most traffic volume of the highways in the standard. The addition of RA in cement stabilized macadam can effectively improve its strength. When both RAP and RA are used as recycled materials, the strength of cement stabilized macadam has little change. 
(2) The gradation of the mixture by stratified recovery is more uniform and the quality of the mixture can be better controlled. If the recovery process is strictly controlled and the uniformity of mixing is enhanced, the quality of the recycled mixture by overall recovery can be improved to a certain extent.

(3) The addition of NA has a negative effect on the dry shrinkage properties of recycled cement stabilized macadam. However, mixing RAP into recycled cement stabilized macadam can reduce the sensitivity of materials to water and enhance the dry shrinkage property of materials.

\section{Acknowledgement}

The authors would like to acknowledge the financial support from the Jiangsu Science and Technology Department (SBE2017740635), and the Yangzhou Science and Technology Bureau (2017062). We also thank the Engineering Testing Centre of Yangzhou University for their support in the experiment.

\section{References}

1. Jiancai Huang, Feng Wang, Yongsong Xiong,etc. Journal of Wuhan Institute of Technology, 37 (09): 57-61. (2015)

2. Menglan Zeng, Zilong Xue, Shi jun Gu,etc. Journal of Beijing University of Technology 41 (04): 579583. (2015)

3. Arpad Horvath, Department of Civil and Environmental Engineering, 9. (2003)

4. Yazhen Sun, Kaixiang Li, Chuanchao Ding, etc. Journal of China \& Foreign Highway, 01:248253.(2018)

5. Minghui Liu, Jinzhou Li, Xingyuan Luo, etc. Construction Technology, S2: 978-981. (2017)

6. John P.Donahue, P.E. , Development and Technology Mo DOT, 11. (2002)

7. Qiang Liu, Ji Lin university (2006)

8. Sihan Liu, Highway 05: 192-196. (2011)

9. Weiwei $\mathrm{Lu}$, Journal of China \& Foreign Highway, 01: 77-79. (2018) 